\title{
O uso do NDVI derivado das imagens Pléiades na análise na estrutura da vegetação em dois fragmentos florestais
}

The use of NDVI derived from Pléiade images in the analysis of the vegetation structure in two forest fragments

El uso de NDVI derivado de imágenes de Pléiade en el análisis de la estructura de la vegetación en dos fragmentos de bosque

Recebido: 30/11/2021 | Revisado: 08/12/2021 | Aceito: 13/01/2022 | Publicado: 14/01/2022

\author{
Anderson da Silva Costa \\ ORCID: https://orcid.org/0000-0002-3955-1817 \\ Amazônia Legal-BIONORTE, Brasil \\ E-mail: anderson.costa@embrapa.br \\ Osmar Alves Lameira \\ ORCID: https://orcid.org/0000-0001-8370-8562 \\ Embrapa Amazônia Oriental, Brasil \\ E-mail: osmar.lameira@embrapa.br
}

\begin{abstract}
Resumo
O índice de vegetação gerado através de imagens de satélites é um dos dados mais utilizados no monitoramento dos parâmetros estruturais da vegetação dos diferentes ecossistemas existente no Brasil. Neste trabalho foi realizada a caracterização do NDVI através das imagens Pléiades com resolução espacial de 2 metros com quatros bandas espectrais, em duas áreas florestais correspondente ao município de Moju-PA cuja localização é 303`14,85409” de latitude sul e 48`59`36,15357" longitude oeste e outra na cidade de Belém-PA localizada a 1²6’30" S de latitude e $48^{\circ} 27^{\prime} 0^{\prime}$ " W de longitude. O processamento das imagens se deu através do software Global Mapper. O máximo valor do NDVI referente à vegetação mais densa alcançou 0,654 enquanto o valor médio foi de 0,500 para área florestal manejada localizada em Moju-PA. No outro fragmento florestal localizado dentro da Embrapa Amazônia Oriental, o valor máximo do NDVI apontou um valor de 0,849 de refletância, sendo que o valor médio alcançou aproximadamente 0,790. O perfil da curva da vegetação gerada através das imagens Pléiades apontou um comportamento positivo para os dois fragmentos florestais, sendo no intervalo de $(0,401$ a 0,654$)$ para floresta manejada de Moju-Pa e de $(0,736$ a 0,849$)$ para a floresta secundária de Belém-PA. Diante dos resultados observados, pode-se concluir que o NDVI, derivado das imagens do satélite Pléiades podem ser usados de maneira confiável na análise e determinação do NDVI.
\end{abstract}

Palavras-chave: Imagens; Pléiades; Estrutura da vegetação; NDVI.

\begin{abstract}
The vegetation index generated through satellite images is one of the most used data in monitoring the structural parameters of vegetation in different ecosystems existing in Brazil. In this work, the characterization of the NDVI was carried out using Pléiades images with a spatial resolution of 2 meters with four spectral bands, in two forest areas corresponding to the municipality of Moju-PA whose location is $3^{\circ} 03^{`} 14,85409^{\prime \prime}$ south latitude and $48^{\circ} 59^{`} 36,15357^{\prime \prime}$ west longitude and another in the city of Belém-PA located at $1^{\circ} 26^{\prime} 30^{\prime \prime} \mathrm{S}$ latitude and $48^{\circ} 27^{\prime} 0^{\prime \prime} \mathrm{W}$ longitude. Image processing was done through the Global Mapper software. Maximum value of the NDVI for the densest vegetation reached 0.654 while the average value was 0.500 for managed forest area located in Moju-PA. In the other forest fragment located within Embrapa Amazônia Oriental, the maximum value of the NDVI indicated a reflectance value of 0.849 , and the average value reached approximately 0.790 . The profile of the vegetation curve generated through Pléiades images showed a positive behavior for the two forest fragments, being in the range of (0.401 to 0.654$)$ for $\mathrm{f}$ forest managed from Moju-Pa and from (0.736 to 0.849) for the secondary forest of Belém-PA. Based on the observed results, it can be concluded that the NDVI, derived from Pléiades satellite images, can be used reliably in the analysis and determination of the NDVI.
\end{abstract}

Keywords: Images; Pleiades; Vegetation structure; NDVI.

\section{Resumen}

El índice de vegetación generado a través de imágenes de satélite es uno de los datos más utilizados en el seguimiento de los parámetros estructurales de la vegetación en diferentes ecosistemas existentes en Brasil. En este trabajo, la caracterización del NDVI se realizó utilizando imágenes de Pléiades con una resolución espacial de 2 metros con cuatro 
bandas espectrales, en dos áreas de bosque correspondientes al municipio de Moju-PA cuya ubicación es 303`14,85409 "latitud sur. y 4859`36, 15357 "de longitud oeste y otra en la ciudad de Belém-PA ubicada a $1^{\circ} 26^{\prime} 30^{\prime \prime} \mathrm{S}$ de latitud y $48^{\circ} 27^{\prime} 0$ "W de longitud. El procesamiento de la imagen se realizó a través del software Global Mapper. Valor máximo del NDVI para la vegetación más densa alcanzó 0.654 mientras que el valor promedio fue de 0.500 para el área forestal manejada ubicada en Moju-PA. En el otro fragmento de bosque ubicado dentro de Embrapa Amazônia Oriental, el valor máximo del NDVI indicó un valor de reflectancia de 0.849, el El valor promedio alcanzó aproximadamente 0,790 . El perfil de la curva de vegetación generado a través de imágenes de Pléiades mostró un comportamiento positivo para los dos fragmentos de bosque, en el rango de $(0,401$ a 0,654$)$ para $\mathrm{f}$ bosque manejado desde Moju-Pa y desde $(0,736$ a $0,849)$ para el bosque secundario de Belém-PA. Con base en los resultados observados, se puede concluir que el NDVI, derivado de las imágenes de satélite de Pléiades, se puede utilizar de manera confiable en el análisis y determinación del NDVI.

Palabras clave: Imágenes; Pléyades; Estructura de la vegetación; NDVI.

\section{Introdução}

De modo geral, as florestas se destacam no panorama ambiental global, por desempenharem um importante serviço ecossistêmico, isto é, as florestas são capazes de estocar carbono na sua biomassa, aérea e subterrânea, em quantidades superiores à existente na atmosfera (Vieira et al., 2008; Ipcc, 2000).

Com o avanço da tecnologia na área do sensoriamento remoto e no processamento de imagens, ocorreu uma melhora na associação das características da estrutura e parâmetros dendrométricos das vegetações com os dados de reflectância, bem como o desenvolvimento de índices de vegetação oriundos das imagens de satélites que tem auxiliado nas estimativas dos parâmetros desejados (Watzlawick et al, 2009).

Segundo Watzlawick (2003), quando comparada aos métodos usuais, a utilização de imagens com grande resolução espacial tem se mostrado como uma alternativa mais viável economicamente, menos danosa ao meio ambiente e com boa precisão para estimar biomassa das comunidades vegetais, uma vez que as reflectâncias apresentam boa relação com o conteúdo dos parâmetros dendrométricos.

O aumento da disponibilidade de dados de Sensoriamento Remoto, juntamente com o desenvolvimento de Sistemas de Informações Geográficas (SIG), tem levado a novas possibilidades de análise geográfica, tanto em escala local quanto global (Nielsen, 2015).

A obtenção simples do NDVI e sua relação direta com a capacidade fotossintética da vegetação é um intermédio para estudos relacionados com características e funções vegetais essenciais como fração de radiação fotossintética absorvida pelo dossel, área foliar, produtividade primária bruta, com inúmeras aplicações na agricultura, silvicultura, ecologia, biodiversidade, analise ambiental, a exemplo da ciclagem de nutrientes, produtividade primária líquida, evapotranspiração, mudança das componentes ambientais, dentre outros (Ponzoni, et al., 2012; Robinson et al., 2017).

Vale ressaltar, que os Índices de vegetação a partir de imagens de satélite podem indicar a qualidade ambiental de uma região. Os índices foram criados com o intuito de ressaltar o comportamento espectral da vegetação em relação ao terreno e facilitam o acompanhamento de áreas preservadas ou ainda da eficiência de técnicas de recuperação de áreas degradadas (Moreira, 2011).

Os índices de vegetação são correlacionados com vários parâmetros da vegetação, como volumetria e biomassa (Huete, 1988). Apesar de já desenvolvidos diversos índices de vegetação, numerosos estudos aprovam a eficiência dos índices Simple Ratio (SR) e o Normalized Difference Vegetacion Index (NDVI), amplamente utilizados (Brandão et al., 2005). O NDVI é a abreviação da expressão em inglês para Normalized Difference Vegetation Index, o que equivale em português a Índice de Vegetação da Diferença Normalizada. Serve para analisar a condição da vegetação natural ou agrícola nas imagens geradas por sensores remotos.

O NDVI é utilizado com sucesso para classificar a distribuição global de vegetação, inferir variabilidades ecológicas e ambientais, produção de fitomassa, radiação fotossintética ativa e a produtividade de culturas (Liu, 2007). 
Vale ressaltar o estudo produzido por Bernardes (1996), que utilizou índices de vegetação para caracterização de florestas na Flona de Tapajós, outro estudo que merece destaque foi do Amaral et al., (1996), onde eles relacionaram índices de vegetação com estágios de crescimento secundário na Floresta Amazônica em Rondônia.

O conhecimento da estrutura do dossel florestal é essencial para melhorar a compreensão da estrutura da floresta, tanto para fins ecológicos, distinção de habitats, bem como, para analisar as variáveis funcionais (Korhonen et al., 2006). Nesse sentido, os dados de sensoriamento remoto têm desempenhado um papel importante no monitoramento de áreas florestais, pois possibilitam o mapeamento de grandes áreas (Devries et al., 2015).

Neste sentido, os ecossistemas florestais precisam ser preservados e pesquisados, um estudo produzido por Costa et al., (2021), aponta a necessidade da expansão de Unidades de Conservação a fim de mitigar os impactos nos ecossistemas amazônicos. Haja vista, que os padrões da biodiversidade requerem técnicas que capturem a complexidade e dinâmica das comunidades e ecossistemas (Magurran, 2013). Por isso, que esses ecossistemas precisam ser conservados e estudados com maior frequência.

Para Ravazzano et al., (2021), a aplicação de um monitoramento por satélite da zona de proteção florestal e a aplicação do uso do NDVI nas imagens analisadas, pode gerar informações ao poder público, das reais dimensões do desmatamento e das áreas ilegalmente ocupadas, bem como da quantidade biótica local, e a saúde das plantas, sendo possível uma rápida respostado Estado, na prevenção de atos ilícitos, consequentemente, evitando que a destruição do ecossistema seja demasiadamente extensa e contribuindo para a manutenção da zona de proteção primária.

Neste sentindo, com o intuito de contribuir com o conhecimento da estrutura da cobertura florestal onde estão inseridas várias espécies florestais, em particular as copaibeiras, este estudo visa entender o comportamento da vegetação através das imagens NDVI derivadas das imagens Pléiades nos fragmentos florestais.

\section{Metodologia}

\subsection{Localização da Área de estudo}

$\mathrm{O}$ estudo foi conduzido em dois fragmentos de áreas florestais, o primeiro fragmento se localiza na fazenda Agroecológica São Roque, entre as coordenadas geográficas 303`14,85409” de latitude sul e 4859`36,15357" longitude oeste, no município de Mojú-PA associado à de Floresta Manejada (Figura 1). Apesar de estar localizada neste município a fazenda Agroecológica São Roque é limítrofe ao município de Tailândia com entrada pela margem direita (sentido Belém/ Marabá da PA-150), vicinal 18, nordeste paraense.

O clima é do tipo Ami (quente úmido) segundo a classificação de Köpen, com temperatura média anual variando entre $25^{\circ} \mathrm{C}$ e $27^{\circ} \mathrm{C}$ e a precipitação média anual oscila de $2.000 \mathrm{~mm}$ a $3.000 \mathrm{~mm}$.

A outra área de estudo está localizada na cidade de Belém-PA, possui uma área de 05 hectares de floresta secundária,

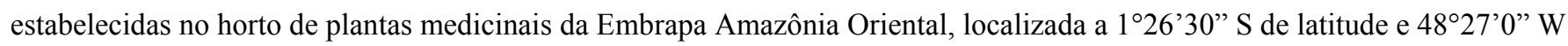
de longitude, com altitude de 10 metros e temperatura média anual de $30^{\circ} \mathrm{C}$ (Figura 1).

O clima em Belém, segundo a classificação de Köppen (1900-1936) é do tipo Afi, ou seja, clima tropical chuvoso de monção. A pluviosidade média anual é de 2.858,7 $\pm 76,6 \mathrm{~mm}$ /ano com maior volume no período chuvoso (dezembro a maio), correspondendo a $71,2 \%$ do total anual, enquanto que os $28,8 \%$ restantes são distribuídos nos meses de junho a novembro (Silva Junior et al., 2012). 
Figura 1. Recorte das imagens Pléiades associadas a vegetação Florestal Manejada em Moju-PA (Imagem A) e a imagem B a floresta secundaria localizada na Embrapa Amazônia Oriental.

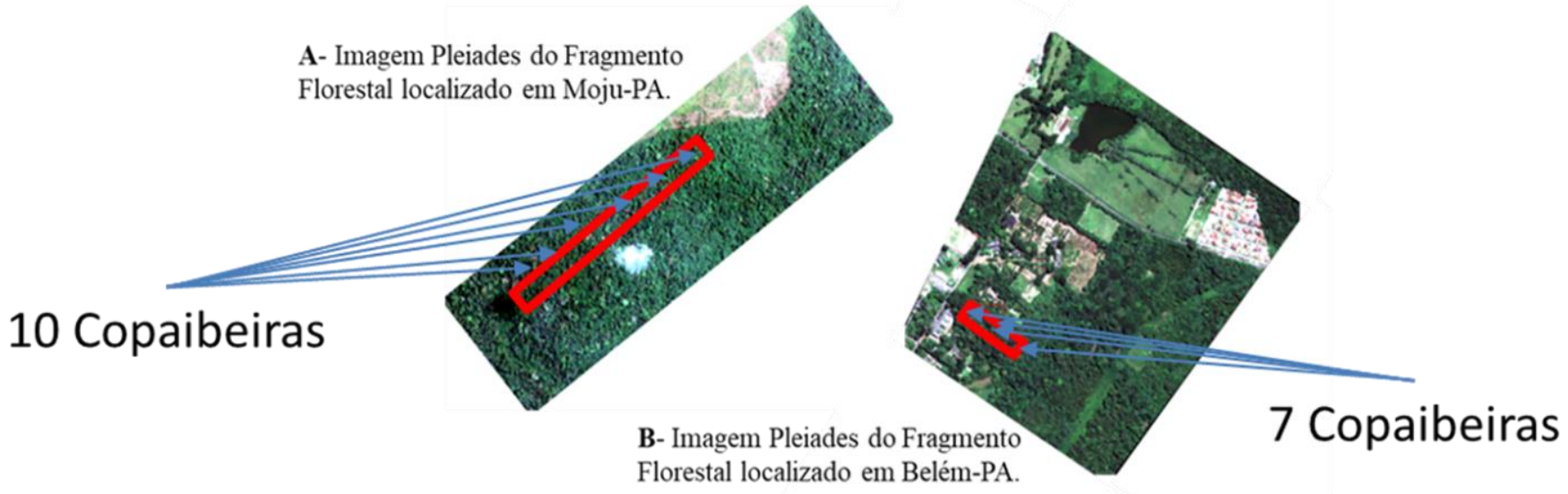

Fonte: Foto autores (2021).

A metodologia consistiu na obtenção de dados provenientes de imagem geradas pelo satélite Pléiades, com alta resolução espacial de 2 metros e com 4 bandas espectrais adquiridas através da Engesat com a dimensão total da cena 20x 20km. Em seguida foi criado um contorno (buffer) ao redor das copaibeiras para identificar o perfil da estrutura florestal a partir dos dados do NDVI através das amostras de 50 pontos aleatório na imagens.

Todos os procedimentos foram realizados em ambiente SIG, utilizando o software Global Mapper. Para geração do NDVI foi utilizado as imagens do Pléiades ortorretificada e com correção atmosférica. As imagens de satélite dessa classe são oferecidas nos mais altos níveis de processamento disponíveis.

Os índices de vegetação foram estimados para cada imagem do satélite Pléiades, adquirida em 26 de maio de 2021 (Belém-PA) e 10 de outubro 2020 (Moju-PA) para o fragmento da cobertura florestal localizada em Moju-PA. Por se tratar de imagens de alta resolução, não foi realizado nenhum tipo de tratamento, dado que a cena utilizada apresentou alta qualidade para o estudo realizado.

A constelação do sistema Pléiades é composta por dois pequenos satélites de grande agilidade que são capazes de adquirir imagens diárias de altíssima resolução espacial em qualquer região do planeta.

O satélite Pléiades possui quatro bandas espectrais, ou seja, Azul: 430-550 nm, Verde: 490-610 nm, Vermelho: 600$720 \mathrm{~nm}$ e Infra-Vermelho próximo: 750-950 nm e, que apresenta resolução espacial de $2 \mathrm{~m}$, com o pixel abrangendo área de 4 $\mathrm{m}^{2}$ (Embrapa, 2013).

Esse estudo tem uma abordagem quantitativa como explica Estrela (2018), a pesquisa quantitativa é uma modalidade de pesquisa composta por variáveis quantificadas em números as quais são analisadas de modo estatístico. O fluxograma abaixo sintetiza as etapas de processamento com a utilização das imagens do satélite Pléiades nas duas áreas de estudos (Figura 2). 
Figura 2. Fluxograma sintetizando as etapas de processamento das imagens Pléiades.

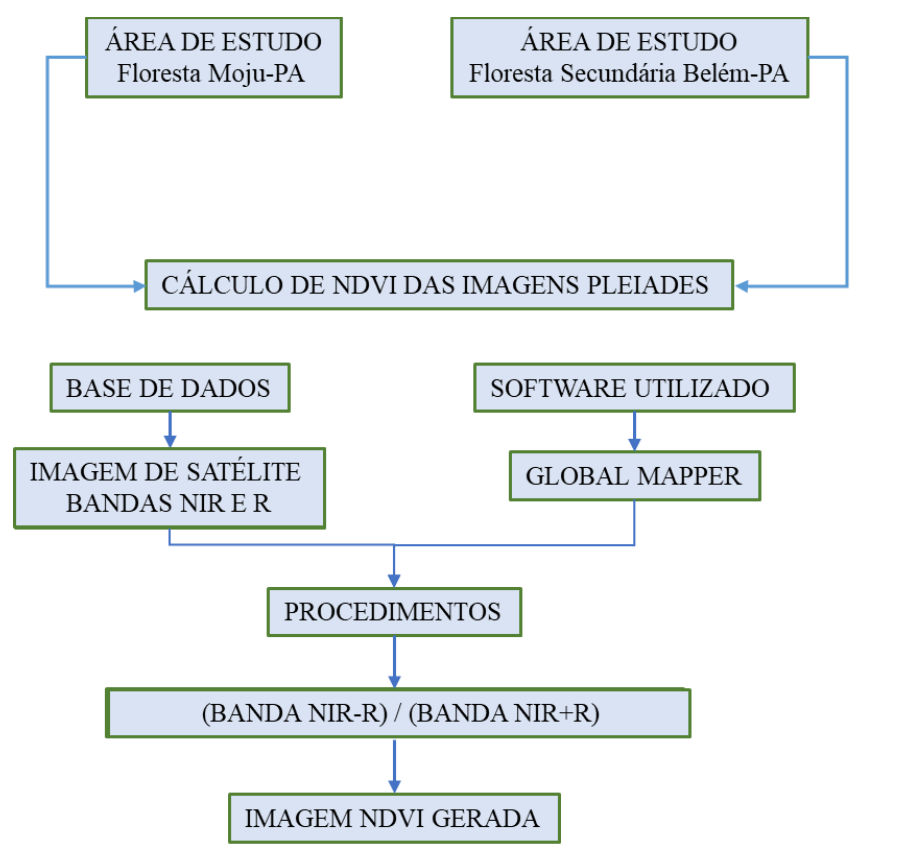

Fonte: Autores (2021).

Para este estudo foram utilizadas as quatro bandas espectrais supracitadas, com base nessas bandas, foram estimados os índices de vegetação NDVI. O Índice de Vegetação por Diferença Normalizada (NDVI) proposto por (Rouse et al., 1973, p. 309) é calculado pela seguinte relação:

$\mathrm{NDVI}=(\mathrm{NIR}-\mathrm{R}) /(\mathrm{NIR}+\mathrm{R})$ onde,

NIR: Reflectância da vegetação na banda do infravermelho próximo;

R: Reflectância da vegetação na banda do vermelho.

Os valores do NDVI variam de -1 à 1, assim quanto mais próximo de 1 maior a densidade da cobertura vegetal, de modo que quanto menor a densidade da vegetação menor o valor do NDVI (Polonio, 2015; Ponzoni \& Shimabukuro, 2007).

\section{Resultados e Discussão}

A partir da geração dos dados de NDVI derivado das imagens Pléiades para as duas regiões de estudos, foram caracterizados os níveis de refletância da vegetação dos fragmentos florestais. Os intervalos de reflectância do NDVI distribuídos espacialmente na Figura 4, associado aos fragmentos florestais da área de Moju-PA, que foram gerados através de 50 amostras tiradas da imagem de NDVI, revelam que os elementos visuais mais representativos são os de valores positivos, o que sugere a presença de cobertura vegetal, os valores de NDVI foram agrupados em quatro classes e seus respectivos alvos de superfície identificados na Tabela 1 .

Tabela 1. Intervalos do NDVI correspondente a suas respectivas classes de superfície.

\begin{tabular}{c|c|c}
\hline \multicolumn{3}{c}{ Fragmento de Floresta Manejada (Moju-PA) } \\
\hline Intervalos NDVI & Classes & Alvos de superfície \\
\hline$(-0,055$ a $-0,223)$ & Classe 1 & Áreas sem vegetação \\
\hline$(-0,022$ a 0,1019$)$ & Classe 2 & Nuvens \\
\hline$(0,625$ a 0,704$)$ & Classe 4 & Sombra \\
\hline$(\mathbf{0 , 4 0 1}$ a $\mathbf{0 , 6 5 4})$ & Classe 5 & Vegetação
\end{tabular}

Fonte: Autores (2021). 
Conforme sugerido pelos intervalos do NDVI, os valores negativos agrupam as áreas sem vegetação (Classe 1), na imagem associada ao fragmento florestal de Moju-PA, ocorreu a presença de nuvens (Classe 2) e sombra (figura 3). Nessa mesma área, o NDVI da vegetação apontou um valor médio de 0,500 de reflectância, com o máximo valor de 0,654 (Tabela 1).

Figura 3. Áreas com a presença da nuvem e sombra em cima do fragmentos florestais localizada em Moju-PA.

\section{Imagem com a presença da sombra da Nuvem}

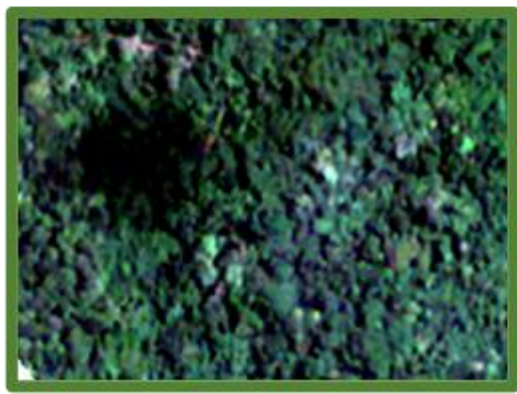

\section{Imagem com a} presença de Nuvem

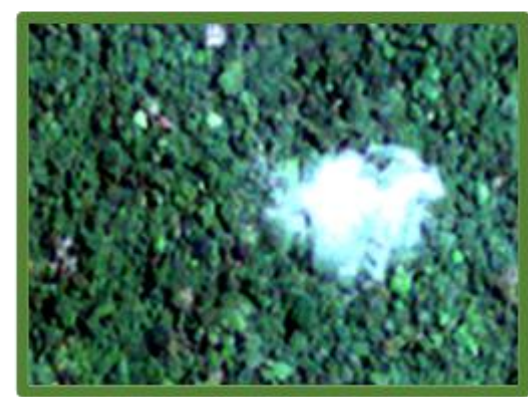

Fonte: Autores (2021).

Um estudo produzido Barros et al., (2020), destacou os resultados que o NDVI apontou para a cobertura vegetativa de Juazeiro do Norte, tendo a máxima o valor de 0,60901. Esse valor próximo a 1 (um) indica uma boa quantidade de cobertura vegetal densa. Dessa forma, a aplicação do NDVI foi relevante para identificar como se encontra a atual situação do município em relação à sua vegetação, pois esse índice pode auxiliar nas tomadas de decisões por parte da gestão pública no planejamento ambiental, uma vez que funciona como indicador de áreas verdes.

Entretanto, quando olhamos as classes associadas aos intervalos do NDVI correspondente ao fragmento florestal da Floresta Secundária (Belém-PA), os dados apontam um valor de refletância maior para vegetação secundária, aproximadamente 0,849 (Tabela 2). Na imagem de Belém-PA não houve a presença de nuvens e sombra.

Tabela 2. Intervalos de NDVI correspondente a suas respectivas classes de superfície.

\begin{tabular}{c|c|c}
\hline \multicolumn{3}{c}{ Fragmento de Floresta Secundária (Belém-PA) } \\
\hline Intervalos NDVI & Classes & Alvos de superfície \\
\hline$(-0,01338$ a $-0,0791)$ & Classe 1 & Áreas sem vegetação \\
\hline$(-0,032$ a $-0,1039)$ & Classe 2 & Água \\
\hline$(\mathbf{0 , 7 3 6}$ a 0,849) & Classe 3 & Vegetação \\
\hline
\end{tabular}

Fonte: Autores (2021).

Vale ressaltar que os resultados variam de $-1 \mathrm{a}+1$ por pixel, de modo que quanto mais próximo de +1 , maior a densidade da vegetação. No fragmento florestal localizado em Moju-Pa, os dados apontaram uma máxima refletância do NDVI de 0,654 (Tabela 2). Na medida em que esse valor diminui, a vegetação vai ficando mais rala, e quanto mais próxima de -1, maior indício de presença de solos descobertos. (Poelking et al., 2007; Melo et al., 2011).

Quando analisamos os dados associado ao desvio médio das refletâncias para as duas áreas de estudos, identificamos um valor de desvio bem baixo para a vegetação, apontando que em média os dados têm baixa oscilação na classe de vegetação (Tabela 3). 
Tabela 3. Intervalos de NDVI correspondente a suas respectivas classes de superfície.

\begin{tabular}{l|c|c|c|c}
\hline Fragmento de Floresta & Média & Máximo & Mínimo & Desvio Médio \\
\hline Floresta Manejada ( Moju-PA) & 0,500 & 0,654 & 0,401 & 0,049 \\
\hline Floresta Secundária (Belém-PA) & 0,790 & 0,849 & 0,736 & 0,025 \\
\hline
\end{tabular}

Fonte: Autores (2021).

A figura abaixo demonstra exatamente essa caracterização de positiva para as áreas com vegetação florestal (Figura 4) e negativa para as áreas sem cobertura florestal (figura 5), colaborando com os estudos produzidos por Barbosa et al., (2017), que registrou os valores mais altos de NDVI, com valores de reflectância agrupados entre $(0,29$ a 0,69), indicando que locais de alta atividade fotossintética, está associado à presença de vegetação verde mais densa. Um estudo produzido por Melo et al., (2011) esclarece que quanto maior for o valor do índice de vegetação, mais densa é a fitomassa verde.

Um outro estudo produzido por Oliveira \& Aquino (2020), apontou que as áreas que mostram tendências negativas, coincidiram principalmente com as de mudança de classe de cobertura da terra, indicando uma redução da vegetação e aumento da área de solo exposto respectivamente. Essas descobertas, demonstram que a análise do NDVI é adequada para detectar áreas de mudança de vegetação sendo relevante sua utilização na gestão ambiental como forma de alcançar a sustentabilidade e manutenção do ambiente.

Figura 4. Cobertura vegetal do fragmento florestal localizado em Moju-PA apontando o NDVI acima de 0,60.

Imagem Pleiades RGB
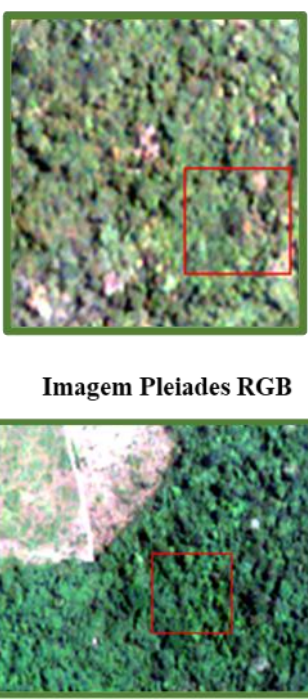

Imagem NDVI

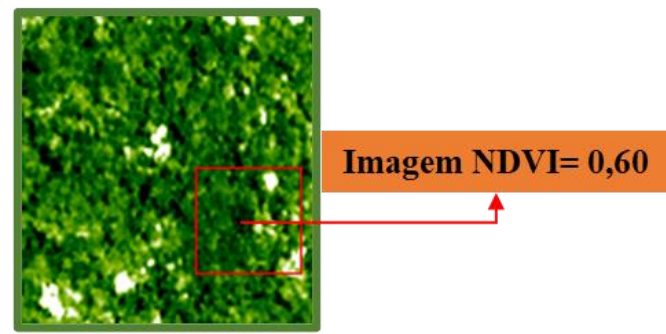

Imagem NDVI

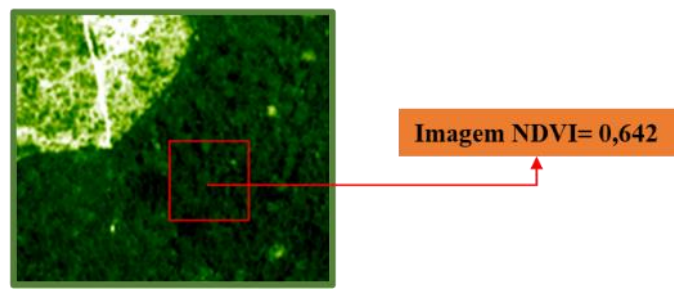

Fonte: Autores (2021).

As áreas sem vegetação registrada na Tabela 1, cujos intervalos de refletância estão no intervalo de (-0,055 a -0,223), são caracterizadas nas imagens como sendo áreas sem a presença de nenhuma cobertura florestal (Figura 5). Essa informação de refletância negativa do NDVI que caracteriza a ausência de vegetação, também foi apontada pelo estudo de Barbosa et al., (2017), onde ele afirma que este comportamento espectral correspondente a presença de solos descobertos, rochas, áreas urbanizadas e outras áreas sem vegetação.

Um estudo produzido por Baptista (2020), apontou que o NDVI retratou uma redução do valor ao longo dos anos, podendo indicar uma menor atividade fotossintética da cobertura vegetal na Área de Proteção Ambiental (APA) na Costa Brava em Santa Catarina. 
Figura 5. Áreas sem vegetação localizado em Moju-PA apontando o NDVI negativo de -0,055 de reflectância.

Imagem Pleiades RGB

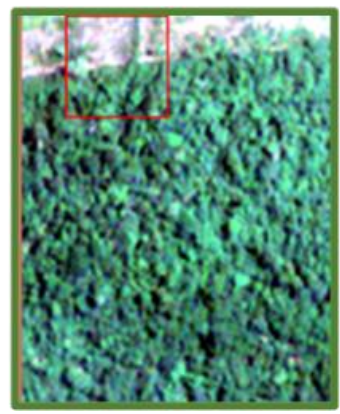

Imagem NDVI

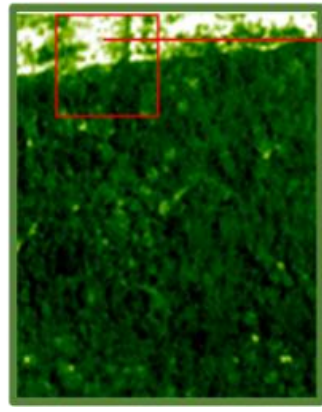

Fonte: Autores (2021).

A floresta secundária localizada na Embrapa Amazônia Oriental apresentou um alto NDVI, como destaca a figura 6. Segundo Barbosa et al., (2017), a relação existente entre o NDVI e as bandas espectrais supracitadas se baseia na assinatura espectral das plantas. Dessa maneira, as porções absorvidas no vermelho e refletidas no infravermelho variam de acordo com as condições das plantas. Quanto mais verdes, nutridas, sadias e bem supridas do ponto de vista hídrico for a planta maior será a absorção do vermelho e maior será a reflectância do infravermelho. Dessa forma, a diferença entre as reflectâncias das bandas do vermelho e do infravermelho será tanto maior quanto mais verde for a vegetação.

Figura 6. Em destaque um ponto da floresta secundária (Belém-PA) com o NDVI acima de 0,767.
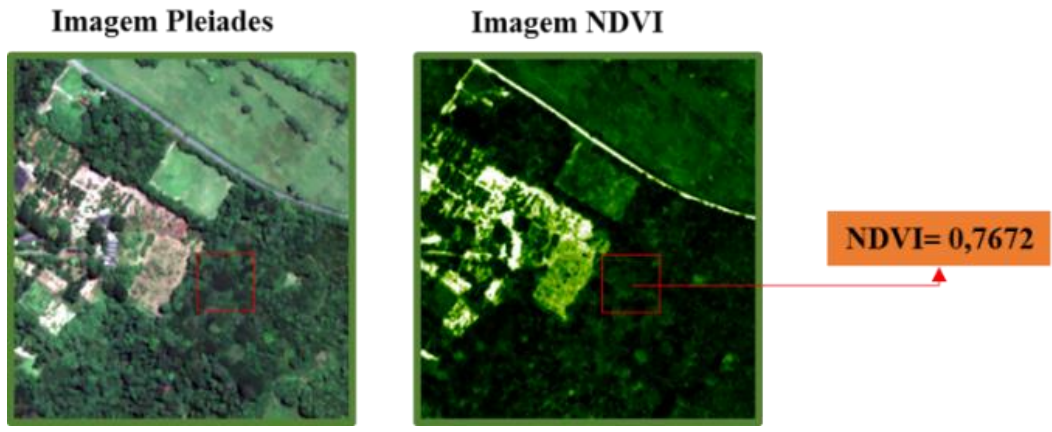

Fonte: Autores (2021).

Um estudo produzido por Pioltine et al., (2018), que aplicou o NDVI sobre a cobertura vegetal da APA da Serra da Mantiqueira, localizada sobrepondo parte dos estados de São Paulo, Rio de Janeiro e Minas Gerais, com o intuito de conhecer a evolução da cobertura vegetal durante um período de 31 anos, desde 1986 a 2017, as áreas que demonstram uma qualidade baixa em virtude, provavelmente, do intensivo uso agrícola, contribuindo para os valores médio de qualidade da vegetação, quanto a conservação da vegetação com NDVI próximo de 0,75 que mostra que há conservação da APA.

Através do comportamento do perfil dos valores de refletância (gerados através das coletas de 50 pontos) derivados do NDVI das imagens Pléiades, apontam que mais de $88 \%$ desses valores se concentraram no intervalo de 0,450 a 0,550 no fragmento florestal de Moju-PA (Figura 7). Em relação ao fragmento de floresta secundária localizada na cidade de Belém-PA, aproximadamente $86 \%$ dos dados se concentraram na faixa de refletância acima de 0,76 (Figura 8). 
Figura 7. Distribuição do NDVI concentrando $88 \%$ na faixa de reflectância acima de 0,420 no fragmento da floresta manejada de Moju-PA.

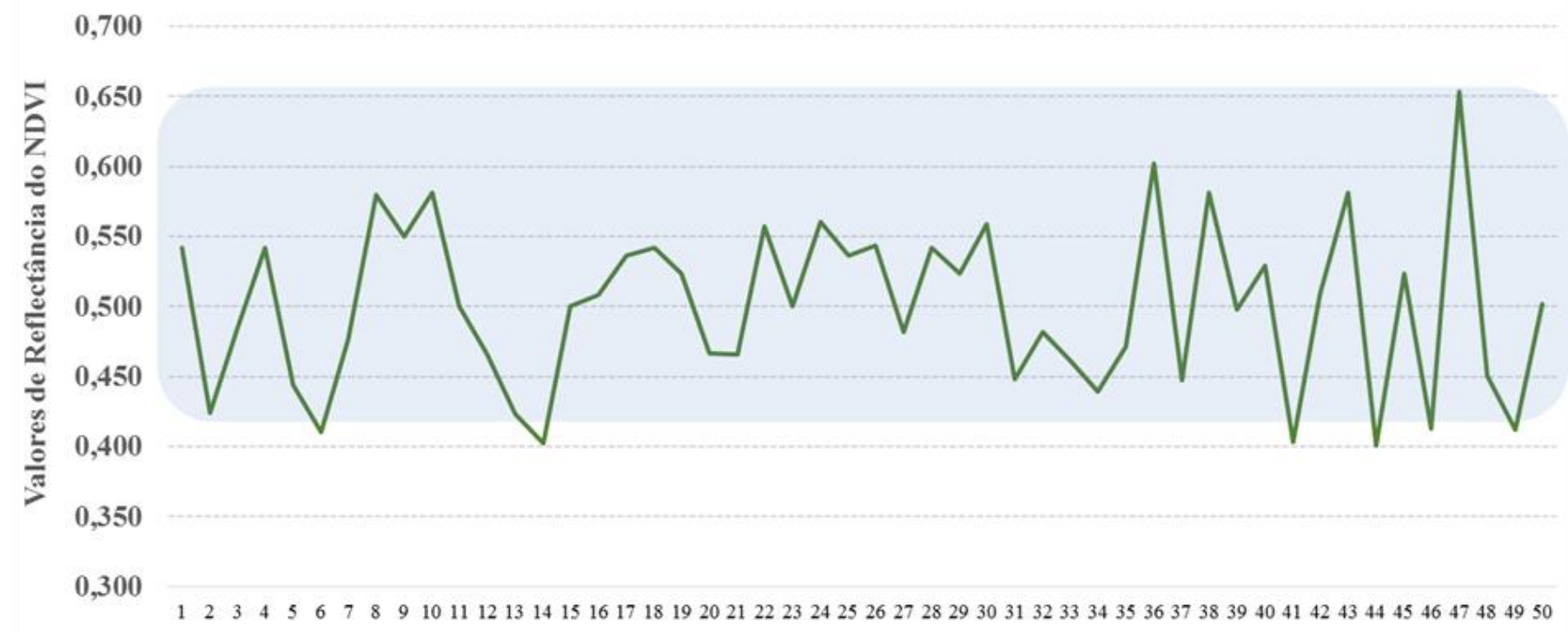
Amostras dos Pixels

Fonte: Autores (2021).

Figura 8. Distribuição do NDVI concentrando $86 \%$ na faixa de reflectância estão acima de 0,76 no fragmento da floresta secundária de Belém-PA.

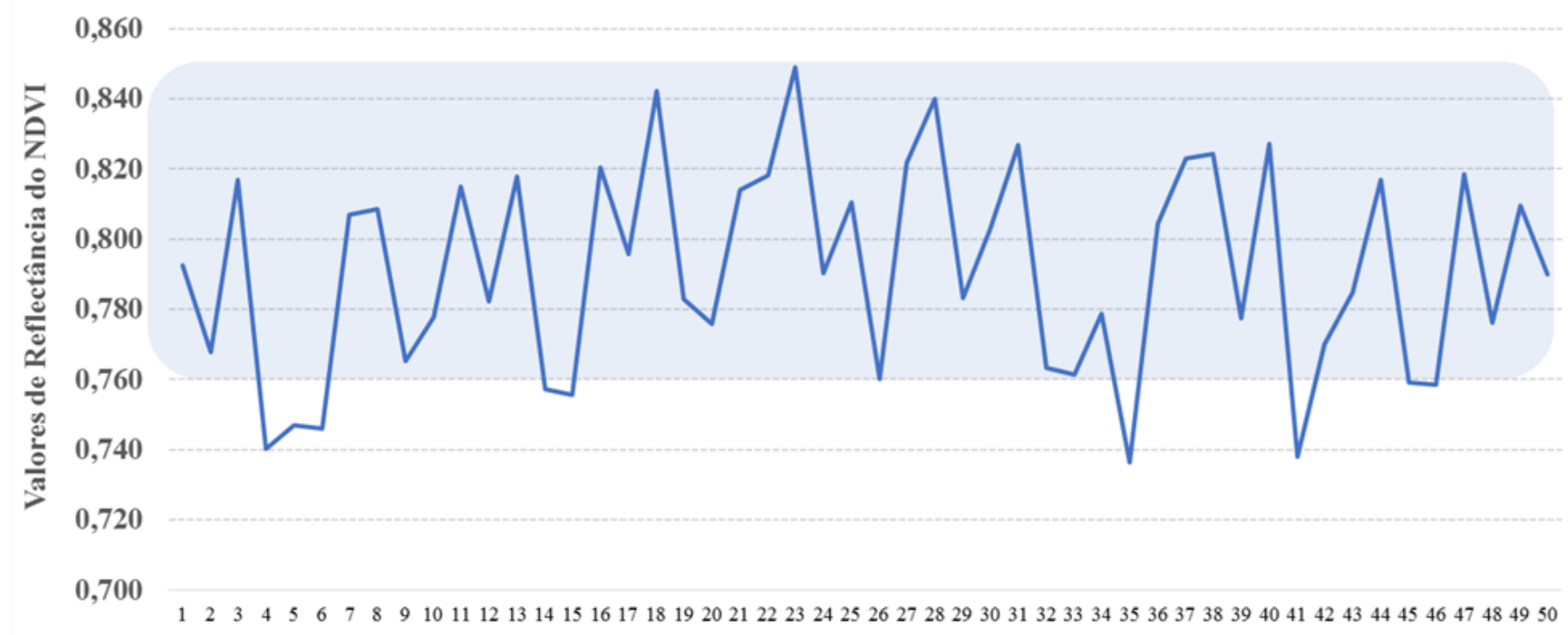

Amostras dos Pixels

Fonte: Autores (2021).

Um estudo produzido por Luz et al., (2021), nos fragmentos de Floresta Estacional Semidecidual Aluvial localizada na Bacia Hidrográfica do Córrego Padre Inácio no Estado de Mato Grosso, apontou variações sazonais nesse tipo de fragmento de floresta, o NDVI variou de 0,5 nos meses mais secos, a 0,9 de refletância nos meses de ocorrência de maior volume de água. 


\section{Conclusão}

O índice de vegetação por diferença normalizada (NDVI) aplicado às imagens do satélite Pléiades mostrou-se uma metodologia simples e de ampla aplicabilidade, além de ser de extrema utilidade nos estudos de análise ambiental da vegetação por sensoriamento remoto.

O perfil da curva da vegetação gerada através das imagens Pléiades apontou um comportamento positivo para os dois fragmentos florestais, sendo no intervalo de $(0,401$ a 0,654$)$ para floresta manejada de Moju-Pa e de $(0,736$ a 0,849$)$ para a floresta secundária de Belém-PA.

As classes de superfícies para o fragmento da floresta manejada foram áreas sem vegetação, nuvem, sombra e vegetação, na segunda área de estudo foram identificados as classes de áreas sem vegetação, água e vegetação na floresta secundária.

Em relação aos dados de mínima e máxima reflectância nas duas áreas de estudos, o NDVI foi maior na floresta secundária, apontando um valor de aproximadamente e 0,736 e 0,849 respectivamente com a média de 0,790 . A obtenção de informações espacialmente detalhadas da vegetação é de suma importância para o manejo florestal sustentável, pois é um número que traduz a condição da vegetação natural.

Entretanto, sugerimos para os próximos trabalhos a utilização de uma série temporal maior para monitorar as variações sazonais ao longo dos anos, no que diz a respeito ao período mais seco e úmido de cada região associado ao seu índice de vegetação.

\section{Referências}

Amaral, S., Soares, J. V., Alves, D. S., Mello, E. M. K., Almeida, S. A. S., Dilva, O. F. \& Silveira, A. M. (1996). Relações entre Índice de Área Foliar (LAI), Área Basal e Índice de Vegetação (NDVI) em relação a diferentes estágios de crescimento secundário na Floresta Amazônica em Rondônia. In: VII Simpósio Brasileiro de Sensoriamento Remoto, Salvador. Anais. Salvador, 485- 489.

Baptista, M. (2020). Análise temporal de NDVI sobre a cobertura vegetal da Área de Proteção Ambiental (APA) Costa Brava em Balneário Camboriú (SC). Metodologias E Aprendizado, 2, 197-202.

Barbosa, A. H. S., Carvalho, R. G. \& Camacho, R. G. V. (2017). Aplicação do NDVI para a Análise da Distribuição Espacial da Cobertura Vegetal na Região Serrana de Martins e Portalegre - Estado do Rio Grande do Norte. Revista do Departamento de Geografia, 33 128-143.

Barros, A. S., Farias, L. M. \& Marinho, J. L. (2020). A Aplicação do Índice de Vegetação por Diferença Normalizada (NDVI) na Caracterização da Cobertura Vegetativa de Juazeiro Do Norte - CE . Revista Brasileira de Geografia Física 13(6), 2885-2895.

Bernardes, S. (1996). Índices de vegetação e valores de proporção na caracterização de floresta tropical primária e estádios sucessionais na área de influência da Floresta de Tapajós-Estado do Pará. Dissertação (Mestrado em Sensoriamento Remoto) - Instituto Nacional de Pesquisas Espaciais.

Brandão, Z. N., Bezerra, M. V. C., Freire, E. C. \& Silva, B. B., (2005). Determinação de Índices de Vegetação usando Imagens de Satélite para uso em Agricultura de Precisão. In: V Congresso Brasileiro de Algodão, V CBA, Salvador, BA, Anais. Campina Grande: CNPA.

Costa, A. S., Queiroz, J. C. B., Chermont, L. S., Lameira, O. A., Souza, E. B., Diniz, M. B., Moura, H. P., \& Costa, D. L. C. (2021). Deforestation forecasts in the Legal Amazon using intervention models. Research, Society and Development, 10 (9).

Devries, B., Verbesselt, J., Kooistra, L. \& Herold, M. (2015). Robust monitoring of small-scale forest disturbances in a tropical montane forest using Landsat time series. Remote Sensing of Environment, 161, 107-121.

Embrapa (2013). Missão Pléiades. <https://www.cnpm.embrapa.br/projetos/sat/conteudo/missao_Pléiades.html〉.

Estrela, C. (2018). Metodologia Científica: Ciência, Ensino, Pesquisa. Editora Artes Médicas.

Huete, A.R. (1988). A soil-adjusted vegetation index (SAVI). Remote Sens. Environ. 25, 295-309, 10.1016/0034-4257(88)90106-X.

IPCC. Intergovernamental Panel On Climate Changes. (2000). Land use, land use change, and forestry special report. Summary for Policymakers. Based on WATSON, R et al. as Core Writing Team. Montreal.

Korhonen, L., Korhonen, K. T., Rautiainen, M. \& Stenberg, P. (2006). Estimation of Forest Canopy Cover: a Comparison of Field Measurement Techniques. Silva Fenicca, 40, 577-588.

Liu, W. T. H. (2007). Aplicações de Sensoriamento Remoto. Editora UNIDERP.

Luz, C. C. S., Ramos, A. W. P., Barros, C. A., Neves, S. M. A. S., Silva, J. S. V. \& Galvanin, E. A. S. (2021). 'NDVI e EVI Aplicados à Análise da Dinâmica Temporal da Cobertura Vegetal e Usos da Terra da Bacia do Córrego Padre Inácio-Mato Grosso, Brasil', Anuário do Instituto de Geociências, vol. 44 : 35438. 
Research, Society and Development, v. 11, n. 1, e54711124170, 2022

(CC BY 4.0) | ISSN 2525-3409 | DOI: http://dx.doi.org/10.33448/rsd-v11i1.24170

Magurran, A. E. (2013). Measuring Biological Diversity. John Wiley \& Sons.

Melo, E. T., Sales, M. C. L. \& Oliveira, J. G. B. (2011). Aplicação do índice de vegetação por diferença normalizada (NDVI) para análise da degradação ambiental da Microbacia Hidrográfica do Riacho dos Cavalos, Crateús - Ce. Raega - O Espaço Geográfico em Análise, v. 23 , p. $520-533$.

Moreira, M. A. (2011). Fundamentos do sensoriamento remoto e metodologias de aplicação. (4a ed.), Atualizada e ampliada. Ed. UFV, 422 p.

Nielsen, M. M. (2015). Remote sensing for urban planning and management: The use of window-independent context segmentation to extract urban features in Stockholm. Computers, environment and urban systems. 52, 1-9.

Oliveira, L. N., \& Aquino, C. M. S. (2000). Índice da Vegetação da Diferença Normalizada (NDVI) na Sub-Bacia Hidrográfica do Rio Gurguéia, Piauí-Brasil: Análise do efeito da expansão agrícola. Revista Geoaraguaia. 10(2), 126-143.

Pioltine, L. F., Maltauro, R. F. \& Pons, N. A. D. (2018). Análise multitemporal de NDVI sobre a cobertura vegetal da APA da Serra da Mantiqueira. In: Congresso Nacional de Meio Ambiente, 15, Poços de Caldas/MG, Congresso: Instituto Federal de Educação Ciência e Tecnologia, 1-5.

Poelking, E. L., Lauermann, A. \& Dalmolin, R. S. D. (2007). Imagens CBERS na geração de NDVI no estudo da dinâmica da vegetação em período de estresse hídrico. In: XIII Simpósio Brasileiro De Sensoriamento Remoto, Florianópolis, Brasil. Anais. Florianópolis: INPE, $4145-4150$.

Polonio, V. D. (2015). Índices de vegetação na mensuração do estoque de carbono em áreas com cana-de-açúcar. 73p. Dissertação (Mestrado em Agronomia: Energia na Agricultura). Universidade Estadual paulista, Faculdade de Ciências Agronômicas de Botucatu.

Ponzoni, F. J. \& Shimabukuro, Y. E. (2007). Sensoriamento remoto no estudo da vegetação. Parêntese Editora.

Ponzoni, F. J., Shimabukuro, Y. E. \& Kuplich, T. M. (2012). Sensoriamento Remoto da vegetação. (2a ed.), Oficina de Textos, 11(3-4), 164p.

Ravazzano, F., \& Silva Falcão, O. E. (2021). A utilização do sistema de monitoramento por NDVI na análise de riscos para concessão de licenciamento ambiental na APA litoral Norte-Ba: uma necessária abordagem das políticas de compliance ambiental. Revista do Programa de Pós Graduação em Direito da UFBA, $31(1), 204-233$

Robinson, N. P. et al. (2017). Dynamic Landsat Derived Normalized Difference Vegetation Index (NDVI) Product for the Conterminous United States. Remote Sensing. 9, 863 .

Rouse, J. W., Haas, R. H., Schell, J. A. \& Deeering, D. W. (1973). Monitoring vegetation systems in the Great Plains with ERTS (Earth Resources Technology Satellite). In: Proceedings Of The Third Erts Symposium, SP-351 Goddard Space Flight Center, Washington: NASA, p. $309-317$.

Vieira, S. A., Aidar, M., Baker, T. R., Camargo, P. B., Chave, J., Delitti, W. B. C., Higuchi, N., Joly, C. A., Martinelli, L. A., Phillips, O. L. \& Trumbore, S. E. (2008). Estimation of biomass and carbono stocks: the case of the Atlantic Forest. Biota Neotropica, 8, 21-29.

Watzlawick, L. F. (2003). Estimativa de biomassa e carbono em floresta ombrófila mista e plantações florestais a partir de dados de imagens do satélite Ikonos II. 28(1), 120 .

Watzlawick, L. F., Kirchner, F. F. \& Sanquetta, C. R. (2009). Estimativa de biomassa e carbono em floresta com araucária utilizando imagens do satélite Ikonos II. Ciência Florestal, 19, 169-181. 